\title{
Selective attention to the color and direction of moving stimuli: Electrophysiological correlates of hierarchical feature selection
}

\author{
LOURDES ANLLO-VENTO and STEVEN A. HILLYARD \\ University of Califormia, San Diego, La Jolla, California
}

\begin{abstract}
Event-related brain potentials (ERPs) were recorded from subjects who attended to pairs of adjacent colored squares that were flashed sequentially to produce a perception of movement. The task was to attend selectively to stimuli in one visual field and to detect slower moving targets that contained the critical value of the attended feature, be it color or movement direction. Attention to location was reflected by a modulation of the early $\mathrm{P} 1$ and N1 components of the ERP, whereas selection of the relevant stimulus feature was associated with later selection negativity components. ERP indices of feature selection were elicited only by stimuli at the attended location and had distinctive scalp distributions for features mediated by "ventral" (color) and "dorsal" (motion) cortical areas. ERP indices of target selection were also contingent on the prior selection of location but initially did not depend on the selection of the relevant feature. These ERP data reveal the timing of sequential, parallel, and contingent stages of visual processing and support early-selection theories of attention that stipulate attentional control over the initial processing of stimulus features.
\end{abstract}

Focusing attention on an object in a visual scene facilitates detection and discrimination of the object's features and those of other stimuli in the immediate surroundings (for reviews, see LaBerge \& Brown, 1989; Van der Heijden, 1992). This attentional focus can be directed toward a specific object or location in the visual field independent of foveation and has been likened to a spotlight (Posner, 1980) or a zoom lens (Eriksen \& St. James, 1986). In general, early-selection theories of attention have proposed that spatial attention acts at an initial stage of sensory registration or encoding and restricts access to higher stages of memory and stimulus identification (e.g., Kahneman \& Treisman, 1984; LaBerge \& Brown, 1989; Luck et al., 1994). Some early-selection theories (e.g., Treisman, 1993; Treisman \& Gelade, 1980; Treisman \& Gormican, 1988) have further suggested that spatial selection is a prerequisite for the correct binding of visual features and, thus, for object identification. Alternatively, late-selection theorists (e.g., Duncan \& Humphreys, 1989, 1992) have argued that stimulus properties, including spatial location, are encoded in parallel

This study was supported by Grant MH-25594 from the National Institute of Mental Health and Grant NS-17778 from the National Institutes of Health, by Contract N00014-89-J-1806 from the Office of Naval Research, and by a postdoctoral fellowship from the San Diego McDonnell-Pew Center for Cognitive Neuroscience to the first author. The authors thank Helen Neville and Steve Luck for their contributions during the inception of this project. Correspondence should be addressed to L. Anllo-Vento, Department of Neurosciences, University of California, San Diego, 9500 Gilman Dr., Dept. 0608, La Jolla, CA 92093-0608 (e-mail: lanllo@ucsd.edu). across the visual field and are processed to levels including object identification.

The relationship between spatial and feature selection may be investigated by recording event-related brain potentials (ERPs) from subjects engaged in attentional tasks. ERPs provide real-time measures of visual processing that help reveal the timing and sequencing of selective operations during the analysis of an object's properties. Previous studies have shown that focusing attention on a specific property of a visual stimulus changes the amplitude of the ERP response. Selection of the relevant spatial location produces an amplitude enhancement of the early positive (Pl at 80-120 msec) and negative ( $\mathrm{N} 1$ at 140-190 msec) components of the visual evoked potential elicited by stimuli at the attended location (Eason, Harter, \& White, 1969; Harter, Aine, \& Schroeder, 1982; Mangun, Hillyard, \& Luck, 1993; Neville \& Lawson, 1987; Van Voorhis \& Hillyard, 1977). The early onset of this attentional modulation of ERP amplitude and its likely origin in extrastriate visual cortical areas (Clark, Fan, \& Hillyard, 1995; Gomez Gonzalez, Clark, Fan, Luck, \& Hillyard, 1994; Mangun et al., 1993) are consistent with a mechanism of sensory gain control over early visual processing (Mangun \& Hillyard, 1990). It has been proposed that such an early-selection mechanism can facilitate the transmission of visual information within the attentional spotlight to higher levels of pattern recognition while suppressing information outside the attentional focus (Hillyard et al., in press; Hillyard, Mangun, Woldorff, \& Luck, 1995).

There is a marked contrast between the early modulation of $\mathrm{P} 1$ and $\mathrm{N} 1$ amplitudes during the spatial focusing 
of attention and the ERPs associated with selectively attending to nonspatial stimulus features, such as color (Hillyard \& Münte, 1984; Wijers, Lamain, Slopsema, Mulder, \& Mulder, 1989), orientation (Harter \& Guido, 1980; Kenemans, Kok, \& Smulders, 1993), shape (Harter et al., 1982), or spatial frequency (Harter \& Previc, 1978; Kenemans et al., 1993; Previc \& Harter, 1982). In all of these cases, the most prominent ERP component elicited by stimuli having the attended feature is a broad selection negativity (SN) that begins between 150 $200 \mathrm{msec}$ poststimulus and extends for another $200 \mathrm{msec}$ or more. This SN tends to be largest over the posterior regions of the scalp and was interpreted by Harter and his colleagues (Harter \& Aine, 1984; Harter et al., 1982) as reflecting the attentional facilitation of processing in feature-specific "channels" of visual input.

The concept of different channels or cortical areas for the processing of specific visual features has received considerable support in recent years from studies of primate neuroanatomy and neurophysiology (Merigan \& Maunsell, 1993; Nakamura, Gattass, Desimone, \& Ungerleider, 1993; Wilson, O'Scalaidhe, \& Goldman-Rakic, 1993) and human functional neuroimaging (Corbetta, Miezin, Dobmeyer, Shulman, \& Petersen, 1991; DeYoe, Bandettini, Neitz Miller, \& Winans, 1994; Sereno et al., 1995; Tootell et al., 1995; Watson et al., 1993; Zeki et al., 1991). Taken together, these studies have found that stimulus features, such as color, pattern, and shape (i.e., features necessary to identify objects), are processed in a "ventral stream" of occipitotemporal visual areas, whereas stimulus properties of movement and spatial relationships are represented in an occipitoparietal "dorsal stream" (reviewed in Ungerleider \& Haxby, 1994). Moreover, human PET studies (Corbetta et al., 1991; Haxby et al., 1991) suggest that paying attention to an individual stimulus feature appears to enhance neural activity in the specific cortical area that encodes that feature, in a manner analogous to Harter and Aine's $(1984,1986)$ proposal of an attentional facilitation of feature-specific channels that is reflected in the $\mathrm{SN}$.

The present study used ERP recordings to gain further information about the respective mechanisms that mediate attention to features represented in the dorsal and ventral visual streams. In particular, the question of whether the selective processing of stimulus features represented in dorsal-stream areas is associated with an ERP pattern such as the $\mathrm{SN}$ has yet to be examined. Accordingly, one aim of the present study was to determine whether the stimulus feature of movement direction, believed to be prominently represented in dorsal-stream area MT (Albright, 1984; Felleman \& Van Essen, 1987), can be used as a cue for attentional selection and whether such selection is associated with an SN component, perhaps having different topographical or timing properties from the $\mathrm{SN}$ associated with attention to a ventral-stream feature such as color.

Previous studies have not only demonstrated that selection by spatial location is reflected in earlier ERP components $(\mathrm{Pl}-\mathrm{Nl})$ than is selection by nonspatial fea- tures (associated with the SN) but also that nonspatial feature selections are hierarchically contingent on prior selection of the relevant location, at least when the attended and unattended locations are easily discriminable (Harter et al., 1982; Hillyard \& Münte, 1984). Hillyard and Münte, for example, found that a substantial SN was elicited by stimuli of the relevant color at an attended location but not by identical stimuli at an unattended location in the opposite visual field. This dependence of feature selection upon an earlier selection by location was taken as evidence in favor of early-selection theories (e.g., Johnston \& Dark, 1982) and, in particular, the hypothesis that selection based on spatial cues predominates over attention to other features (Treisman \& Gelade, 1980; Treisman \& Gormican, 1988). Consequently, a second major aim of the present study was to determine whether selection of a dorsal-stream feature, movement direction, is contingent upon spatial attention in the same way as is selection of the ventral-stream feature of color.

These questions were examined in an experimental design in which stimuli were flashed in a rapid, randomized sequence to the right and left visual fields. Each stimulus consisted of a pair of adjacent, briefly flashed squares separated by a short interval, so as to produce a perception of movement from the location of the first square to the location of the second (see Figure 1). On an equiprobable basis, each stimulus moved either vertically or horizontally and was colored either red or blue. Subjects attended to stimuli in one visual field at a time and responded to infrequent targets having the attended feature value and a slower apparent

\section{LVF Horizontal}

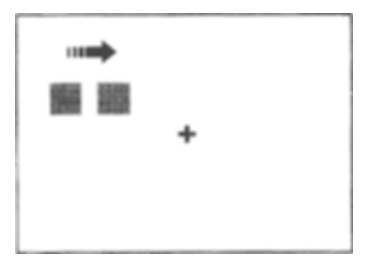

LVF Vertical

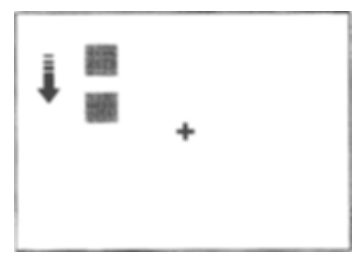

RVF Horizontal

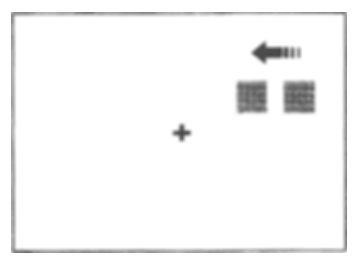

RVF Vertical

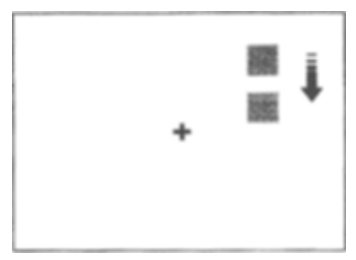

Figure 1. Stimuli were presented to the left and the right visual field ( $L V F$ and RVF, respectively) in random order. Each stimulus consisted of a pair of briefly flashed squares separated by a short interval ( 50 or $150 \mathrm{msec}$ ), so as to produce a perception of movement from the location of the first to the location of the second. Stimuli could move in the vertical or horizontal direction and could be blue or red in color, equiprobably. Standard stimuli (50-msec SOA) were presented $90 \%$ of the time and target stimuli (150-msec SOA) were presented $10 \%$ of the time. 
movement. ERPs could then be compared for stimuli in attended and unattended visual fields and for stimuli having the attended or unattended value of the color and movement-direction features.

\section{METHOD}

\section{Subjects}

Twelve subjects $(7$ women, 5 men; age range $=18-35$ years, $M=22$ years) participated in the study as paid volunteers; 2 of the subjects ( 1 woman, 1 man) were left-handed. All subjects had normal or corrected-to-normal vision.

\section{Stimuli}

Each stimulus consisted of a pair of sequentially flashed squares $\left(0.9^{\circ} \times 0.9^{\circ}\right)$, the second of which was always centered $2^{\circ}$ above the horizontal meridian and $7.3^{\circ}$ to the left or the right of the fixation cross at a viewing distance of $65 \mathrm{~cm}$ (Figure 1). The first flash of the pair was centered $0.5^{\circ}$ higher or more peripheral than the second, thereby producing the perception of a vertical downward or horizontal inward moving square, which could be either red or blue. Thus, there were four types of stimulus pairs, defined by orthogonal combinations of color and direction of motion-red vertical, blue vertical, red horizontal, and blue horizontal--which were presented equiprobably and randomly to either the left or the right hemifield.

The duration of each flash in the pair was $33 \mathrm{msec}$, with a stimulus onset asynchrony (SOA) of $50 \mathrm{msec}$ on standard trials $(p=$ .9) and of $150 \mathrm{msec}$ on target trials $(p=.1)$. Due to the longer SOA, target stimuli were most often perceived as a rapid sequence of two separate flashes, although some subjects reported seeing these infrequent stimuli as a single slowly moving square.

The 496 stimuli in each block were randomly sampled from 16 stimulus classes defined by color (red/blue), direction of motion (horizontal/vertical), SOA duration (standard/target), and visual hemifield (right/left). Interstimulus intervals (ISIs) varied at random between 280 and $580 \mathrm{msec}$ (rectangular distribution).

\section{Procedure}

Each subject was tested in two recording sessions on separate days, each lasting about $2 \mathrm{~h}$. The subject was comfortably seated in a reclining chair and was trained to maintain fixation on the central cross while discriminating the infrequent targets from the more common standards. At the beginning of each block of trials, the subjects were reinstructed to maintain fixation on the central cross. At the same time, they were told to attend to either a specific color (red or blue) or a specific direction of motion (horizontal or vertical) in either the left or the right hemifield. Thus, there were eight experimental conditions in all: attend vertical right, attend horizontal right, attend blue right, attend red right, attend vertical left, attend horizontal left, attend blue left, and attend red left. The order of presentation of these attention conditions was counterbalanced across sessions and subjects. Each session included two blocks of each of the eight possible combinations of feature and location.

The subjects were instructed to press a button every time they detected a target (i.e., a pair of flashes separated by an SOA of $150 \mathrm{msec}$ ) having the attended feature-location combination. The hand used by the subject to respond to the targets was switched midway through the session, and the order was counterbalanced across sessions and subjects. The subjects received feedback on their behavioral performance and their ability to sustain fixation at the end of each block.

Electrophysiological recording. The EEG was recorded from nonpolarizable electrodes mounted in an elastic cap and placed at mirror-image scalp locations over frontal, central, parietal, occipital, anterior temporal, posterior temporal, and occipitotemporal areas (International 10/20 System sites F3, F4, C3, C4, P3, P4, O1, $\mathrm{O} 2, \mathrm{~T} 3, \mathrm{~T} 4, \mathrm{~T} 5$, and T6, plus left occipital (OL) and right occipital (OR) sites located halfway between $\mathrm{O} 1$ and $\mathrm{T} 5$ and between $\mathrm{O} 2$ and $T 6$, respectively). The algebraic average of the right and left mastoids was computed off line and was used as a reference. An electrode placed below the left eye served to monitor eye blinks, and the horizontal electrooculogram (HEOG) was recorded from electrodes placed $1 \mathrm{~cm}$ lateral to the right and left external canthi. EEG and EOG activity was amplified with a bandpass of $0.01-100 \mathrm{~Hz}$ and digitized at $250 \mathrm{~Hz}$.

EEG and EOG traces were monitored on line in order to detect small eye movement deviations while the subject performed the task. Blocks having discernible eye movements were aborted and restarted.

ERPs were averaged off line using a computer program that extracted overlapping epochs of the EEG beginning $1,000 \mathrm{msec}$ before the triggering stimulus (i.e., first stimulus of each pair) and continuing for $1,000 \mathrm{msec}$ poststimulus. Artifact rejection was performed before averaging to remove epochs containing blinks, eye movements, muscle activity, or amplifier blocking. On average, $22 \%$ of the trials were rejected due to a combination of these artifact sources, with blinks and eye movements being the most frequent cause for rejection. In addition to this procedure for the detection of artifacts, a second method was used to ensure the absence of systematic changes in fixation that could potentially contaminate the spatial attention effects. For this purpose, ERPs and EOG were averaged over the course of an entire block of trials. If the subjects had systematically moved their eyes toward the attended visual field location, the horizontal EOG traces would show deviations as a function of the hemifield being attended.

Table 1

Characteristics of Early ERP Components Elicited by Standard Stimuli

\begin{tabular}{|c|c|c|c|c|c|c|c|c|}
\hline \multirow[b]{3}{*}{ Component } & \multicolumn{4}{|c|}{ Peak Latency } & \multirow{3}{*}{$\begin{array}{c}\text { Measurement } \\
\text { Window }\end{array}$} & \multirow[b]{3}{*}{ Laterality } & \multirow[b]{3}{*}{$V \times H^{*}$} & \multirow[b]{3}{*}{$L \times V \times H^{*}$} \\
\hline & \multicolumn{2}{|c|}{ Ipsi } & \multicolumn{2}{|c|}{ Contra } & & & & \\
\hline & $M$ & $S E M$ & $M$ & $S E M$ & & & & \\
\hline Posterior $\mathrm{Cl}$ & 80 & \pm 2.5 & & & $50-75+$ & Ipsi & $p<.04$ & n.s. \\
\hline Posterior P1 & 134 & \pm 13.2 & 104 & \pm 20.0 & $75-100$ & Contra & $p<.002$ & $p<.02$ \\
\hline Posterior NI & 173 & \pm 18.6 & 162 & \pm 15.8 & $160-190$ & Contra & $p<.003$ & $p<.001$ \\
\hline Posterior P2 & 230 & \pm 4.6 & 225 & \pm 6.3 & $180-250$ & Symmet & n.s. & n.s. \\
\hline Anterior N1 & 138 & \pm 6.7 & 141 & \pm 4.5 & $120-150$ & Contra & $p<.001$ & $p<.002$ \\
\hline Anterior P2 & 197 & \pm 8.1 & 199 & \pm 4.2 & $190-205$ & Contra & $p<.05$ & $p<.05$ \\
\hline
\end{tabular}

Note-Peak latency and measurement window are expressed in milliseconds. *Probability values for ANOVA interactions showing laterality effects: $\mathrm{L}=$ attended location ( $\mathrm{L}+\mathrm{vs} . \mathrm{L}-$ ); $\mathrm{V}=$ visual field; $\mathrm{H}=$ hemisphere; $n . s .=$ not significant. TThe possibility of an independent attention effect on $\mathrm{Cl}$ was tested by measuring its amplitude during it rising phase $(50-75 \mathrm{msec})$; see Note 1 . 
These long horizontal EOG averages revealed no systematic changes in eye position with changes in the direction of attention.

Because of the short ISIs used in this study (280-580 msec), the ERP responses to successive stimuli overlapped and thus distorted the final ERP averages. Accordingly, a procedure to remove the estimated overlap from these ERP waveforms was implemented (Woldorff, 1993). The absence of significant ERP activity in the baseline prior to stimulus presentation was indicative of successful overlap removal.

Data analysis. ERPs were averaged separately for each type of stimulus, attention condition, and electrode location. Averages included only ERP responses elicited on behaviorally correct trials. Amplitudes of all components were calculated with respect to the mean voltage over the $200-\mathrm{msec}$ preceding stimulus onset. The earlier components were quantified as mean amplitudes within a specified time window centered around the peak latency in the grand-average waveform (see Table 1).

Repeated measures analyses of variance (ANOVAs) were carried out with the following factors: attended feature (color vs. motion); attended versus unattended value of the relevant feature $(\mathrm{F}+$ vs. $\mathrm{F}-$ ); attended versus unattended location $(\mathrm{L}+\mathrm{vs.} \mathrm{L}-$ ); visual field of stimulus presentation (left vs. right); electrode site (for anterior components, $\mathrm{F} 3 / \mathrm{F} 4$ and $\mathrm{C} 3 / \mathrm{C} 4$; for posterior components, $\mathrm{P} 3 / \mathrm{P} 4, \mathrm{O} 1 / \mathrm{O} 2, \mathrm{OL} / \mathrm{OR}$, and T5/T6); and hemisphere (left vs. right). The Greenhouse-Geisser correction was used for all tests that included more than two electrode locations; in those cases, the $p$ values reported include the corresponding adjustment to the degrees of freedom (Vasey \& Thayer, 1987).

Behavioral performance was measured in terms of reaction times (RTs) and percentage of correct responses (hits) for responses made 200-1,000 msec following each relevant target stimulus; all other responses were classified as false alarms (FAs).

\section{RESULTS}

\section{Behavioral Responses}

RTs varied according to the feature being attended, with responses to targets of the attended color being faster than responses to targets moving in the attended direction $(615$ vs. $630 \mathrm{msec})[F(1,11)=17.7, p<.002]$. In addition, there was a significant interaction between attended feature and visual field, such that color targets appearing in the right visual field were associated with faster responses than were those appearing in the left visual field (607 vs. $624 \mathrm{msec}$ ); however, motion targets did not show this right visual field advantage (right, $630 \mathrm{msec}$; left, $631 \mathrm{msec})[F(1,11)=6.41, p<.03]$.

The percentage of correct target detections ranged from $54 \%$ to $90 \%$ in different subjects, with an average of $74 \%$. A higher rate of correct detections was obtained when the subjects were attending to color than when they were attending to motion direction $(78 \%$ vs. $71 \%)[F(1,11)=$ $26.7, p<.001]$. Despite the difficulty of the target discrimination, the mean percentage of FAs was very low $(<1 \%)$, indicating that the subjects were conservative in their decision criteria. Not surprisingly, the percentage of FAs was greater in response to nontargets at the attended location than at the unattended location $(1.2 \% \mathrm{vs}$. $0.7 \%)[F(1,11)=9.01, p<.02]$.

\section{Electrophysiological Recordings}

ERPs to standard stimuli. Figures 2 and 3 display the ERP waveforms elicited by right visual field standard (nontarget) stimuli during the attend-color and attend- motion conditions, respectively; equivalent ERPs were obtained with left visual field stimuli. ERPs were averaged separately in response to four stimulus categories: standards with the attended feature at the attended location $(F+L+)$, standards with the attended feature at the unattended location $(\mathrm{F}+\mathrm{L}-)$, standards without the attended feature at the attended location $(F-L+)$, and standards without the attended feature at the unattended location $(\mathrm{F}-\mathrm{L}-)$. Separate averages were obtained for the attend-color and attend-motion conditions.

ERPs to all types of standards were characterized by an early $\mathrm{Cl}$ negativity peaking at about $75 \mathrm{msec}$, followed by posterior $\mathrm{P} 1, \mathrm{~N} 1$, and $\mathrm{P} 2$ components. The frontal and central ERPs were characterized by shorter latency $\mathrm{N} 1$ and $\mathrm{P} 2$ deflections (see Table 1). In addition, the attended stimuli $(\mathrm{F}+\mathrm{L}+)$ elicited an $\mathrm{SN}$ and late positive component (LPC) that were largest over centroparietal scalp. All of these components were very similar in the attend-color and attend-motion conditions.

Spatial attention effects. As can be seen in Figures 2 and 3, stimuli appearing at the attended location, regardless of whether or not they bore the attended feature (i.e., $\mathrm{F}+\mathrm{L}+$ or $\mathrm{F}-\mathrm{L}+$ ), elicited enlarged amplitudes of the posterior P1, N1, and P2 components, as well as of the anterior $\mathrm{N} 1$ wave. This amplitude modulation of the ERP waveform as a function of spatial attention can be seen in the difference waves (Figure 4) obtained by subtracting the ERPs averaged across all standards at the unattended location $(\mathrm{L}-$ ) from the ERPs to all standards at the attended location $(\mathrm{L}+)$. It is evident that the spatial attention effects were very similar in the attend-color and attend-motion conditions.

There was no significant effect of attention upon the $\mathrm{Cl}$ component $[F(1,11)=3.95, p>.05]$, which could be observed in the raw waveforms (Figures 2 and 3 ) but not in the difference waves (Figure 4). ${ }^{1}$ This early negativity was largest over the more medial occipital sites $[F(5,55)=$ 5.3, $p<.02$ ] of the ipsilateral hemisphere (see Table 1) and did not differ in amplitude or topographical distribution as a function of the type of feature being attended. The earliest attentional modulation was observed on the amplitude of P1, which was larger in response to stimuli at the attended location, both for attention to color and for attention to direction of motion $[F(1,11)=18.6, p<$ $.002]$. This attention effect was maximal at the occipital and occipitotemporal electrode sites (Figure 5) and was initially larger contralaterally (75-100 msec poststimulus) but then became larger ipsilaterally $(125-150 \mathrm{msec})$ $[F(1,11)=8.23, p<.02$, and $F(1,11)=4.8, p<.05$, respectively, for attended location $\times$ visual field $\times$ hemisphere interaction within the two intervals].

Like the P1, the posterior N1 was also significantly enlarged when evoked by stimuli at the attended location $[F(1,11)=80.4, p<.001]$, with the magnitude of the enhancement being larger over contralateral than over ipsilateral sites $[F(1,11)=15.9, p<.001]$. This contralateral distribution of the spatial attention effect on $\mathrm{N} 1$ tended to be more pronounced when attending to color than when attending to motion direction [attended fea- 


\section{Attend Color Standards}
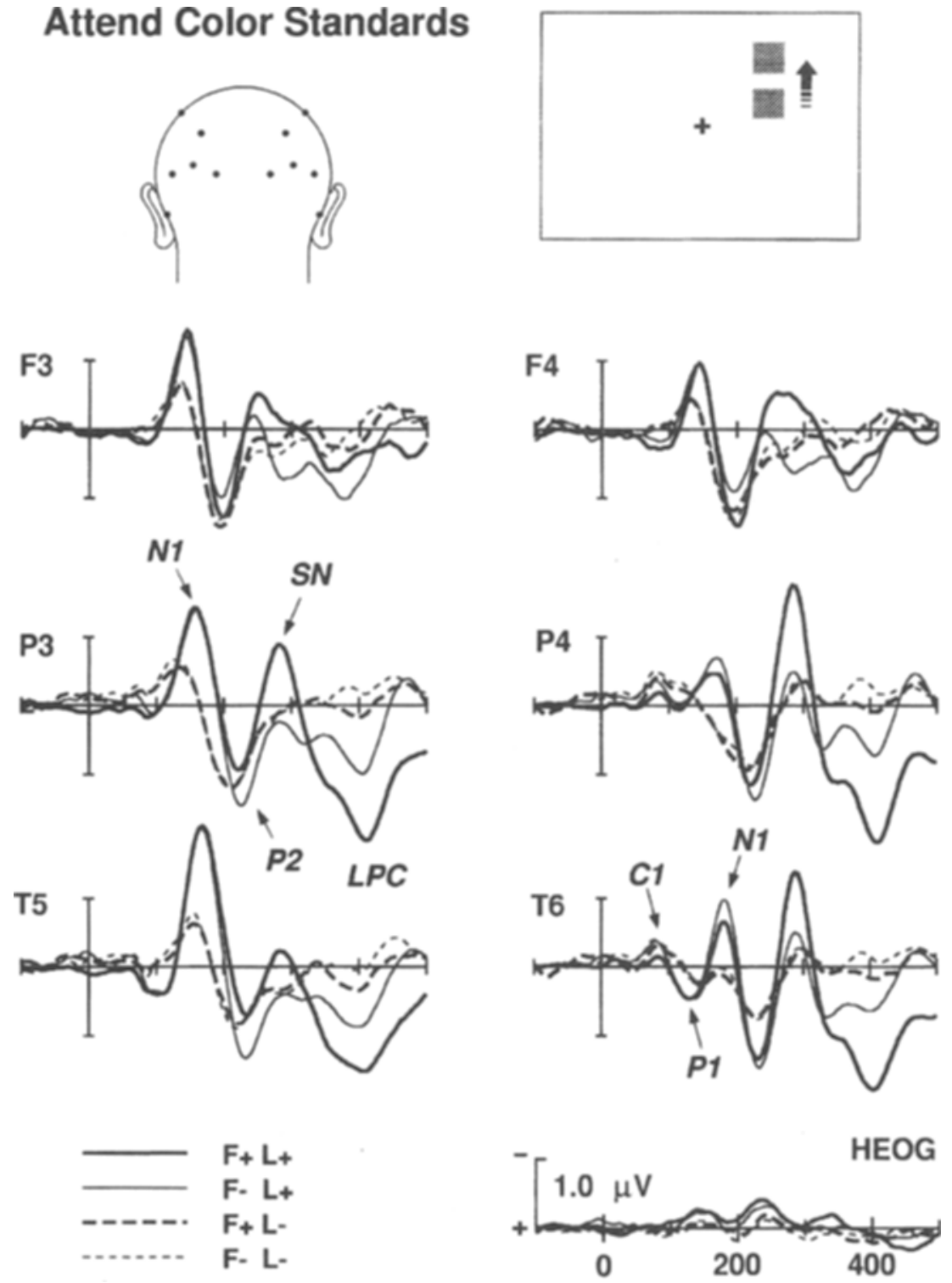

Figure 2. Grand-average ERPs across 12 subjects in the attend-color condition in response to four types of standard (nontarget) stimuli appearing in the right visual field. ERPs were elicited by moving colored squares where both the color feature and the location were attended $(F+L+)$, the location was attended but not the color $(F-L+)$, the color was attended but not the location $(F+L-)$, or neither attribute was attended $(F-L-)$. Waveforms shown were averaged across red stimuli when red was attended and blue stimuli when blue was attended $(F+)$, or across red standards when blue was attended and blue standards when red was attended $(\mathrm{F}-)$, regardless of the direction in which they moved (vertical or horizontal). ERPs shown are from left and right frontal (F3/F4), parietal (P3/P4), and temporal (T5/T6) sites. HEOG refers to bipolar recordings of horizontal eye position.

ture $\times$ attended location $\times$ visual field $\times$ hemisphere $\times$ electrode site, $F(3,33)=4.48, p<.009]$ (Figure 5). The anterior $\mathrm{N} 1$ component also showed an amplitude enhancement as a function of spatial attention $[F(1,11)=$ $14.11, p<.004]$ that was greater contralaterally $[F(1,11)=$ $19.42, p<.002]$. The posterior $\mathrm{P} 2$ wave was larger for responses to attended field stimuli $[F(1,11)=8.32, p<$ $.02]$, particularly at the occipital and occipitolateral sites
$[F(3,33)=7.89, p<.003]$. However, the anterior $\mathrm{P} 2$ wave was not significantly enlarged by spatial attention.

Although reliable effects of spatial attention were also observed on the SN and LPC components, these changes interacted with the effects of feature attention and, hence, are described below.

Feature attention effects. To examine feature selection effects, difference waves were calculated by sub- 


\section{Attend Motion Standards}
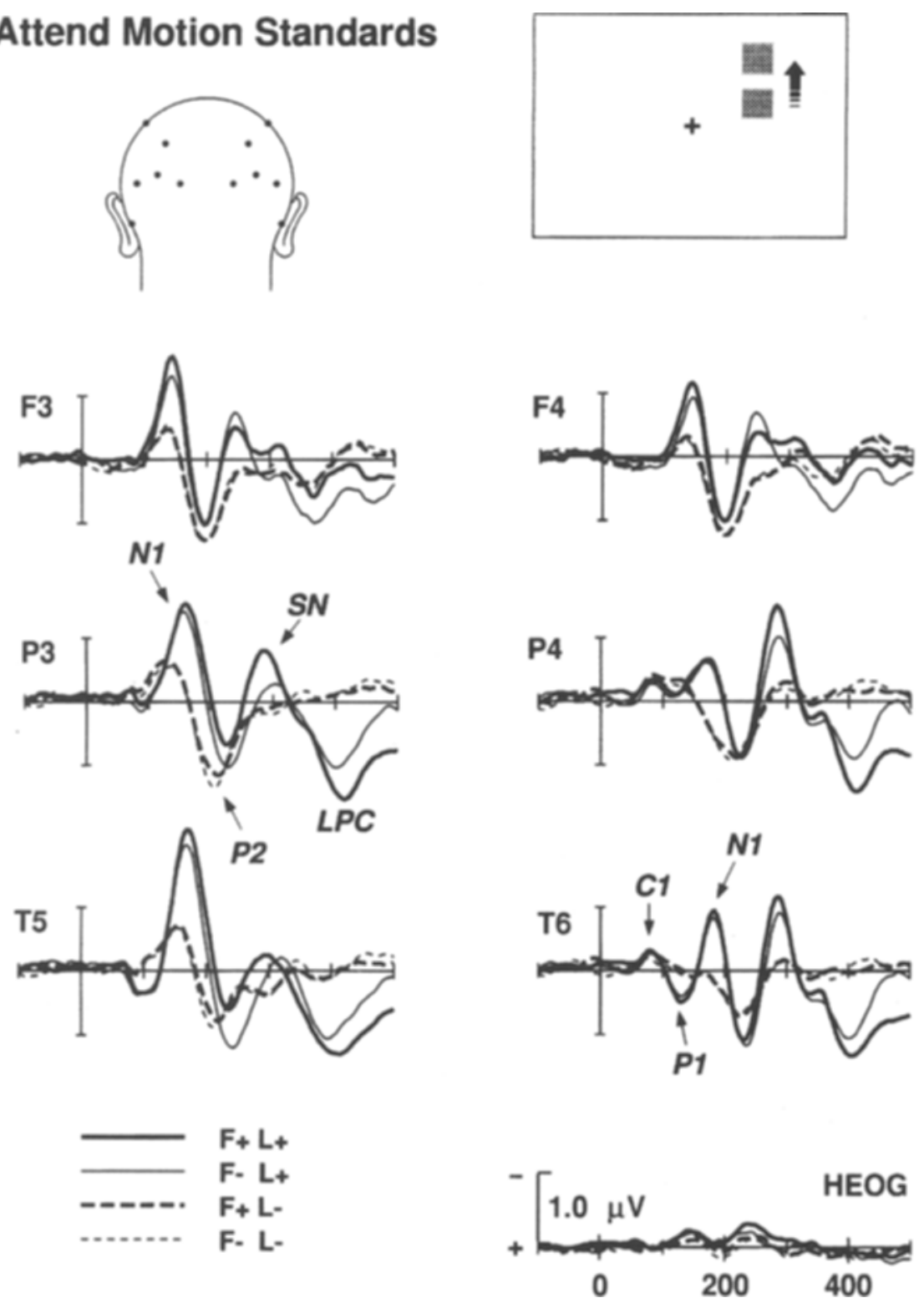

Figure 3. Grand-average ERPs across 12 subjects in the attend-motion condition in response to right visual field standard stimuli. As in Figure 2, ERP waveforms were averaged according to whether the location and direction of movement were attended $(F+L+)$, the location was attended but the movement direction was unattended $(F-L+)$, the location was unattended but the motion was attended $(F+L-)$, or neither feature was attended $(F-L-)$. Waveforms shown were averaged across vertically moving stimuli when the vertical direction was attended and horizontally moving stimuli when the horizontal direction was attended $(F+)$, or vertically moving stimuli when the horizontal direction was attended and horizontally moving stimuli when the vertical direction was attended ( $F-$ ). Electrode positions and components are labeled as in Figure 2.

tracting ERPs to stimuli having the unattended value $(\mathrm{F}-)$ of the relevant feature (either color or motion) from the ERPs to the stimuli having the attended value $(F+)$. This subtraction was made for stimuli both at the attended location [i.e., $(\mathrm{F}+\mathrm{L}+)-(\mathrm{F}-\mathrm{L}+)]$ and at the unattended location [(i.e., $(\mathrm{F}+\mathrm{L}-)-(\mathrm{F}-\mathrm{L}-)]$. As seen in Figures 6 and 7, selection for both color and motion features was reflected by a broad SN beginning at 150
200 msec, preceded anteriorly by a small selection positivity (SP) and followed posteriorly by an LPC. These components were markedly larger for feature selections at the attended location than at the unattended location (compare right and left columns in Figures 6 and 7).

The SN consisted of an earlier phase (150-225 msec) with greater negativity over the posterior scalp contra- 


\section{Location Selection}

(L+) - (L-)

\section{Contralateral}
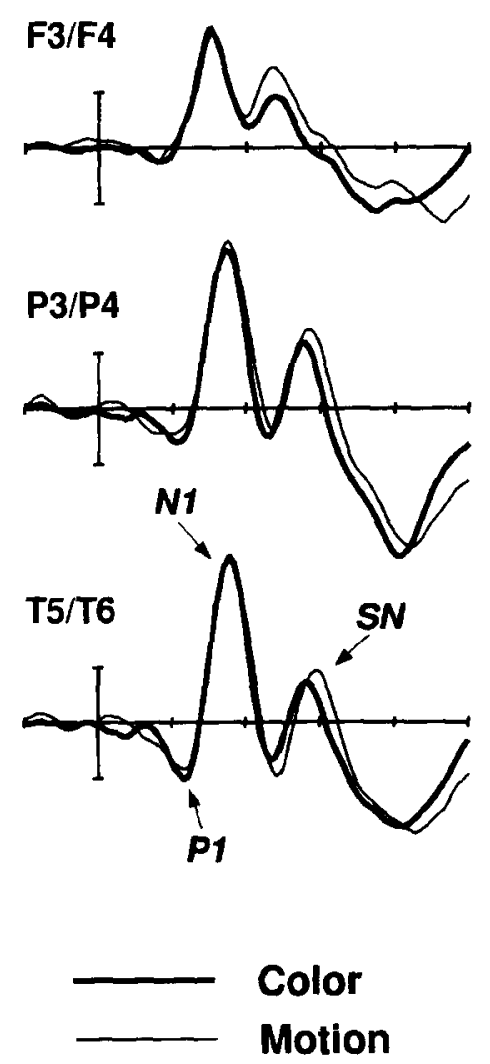
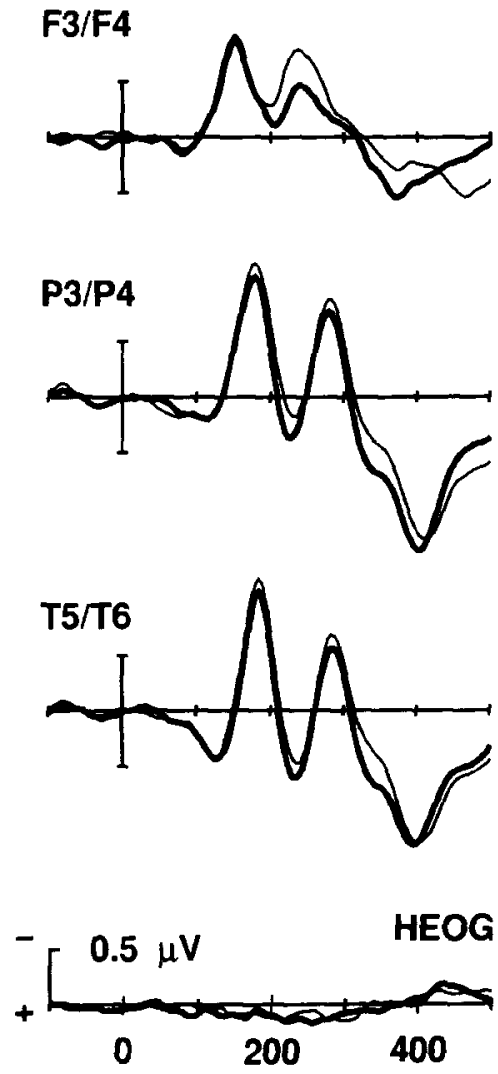

Figure 4. Difference waves obtained by subtracting grand-average ERPs to all standard stimuli presented in the unattended location $(L-)$ from the ERPs to all standards presented in the attended location $(L+)$. ERPs were averaged across stimuli with the attended feature value $(F+)$ and without the attended feature $(F-)$. Separate difference waves were calculated for the hemisphere contralateral (left column) and ipsilateral (right column) to the visual field of the stimulus. Superimposed traces correspond to the attend-color (thick line) and attend-motion (thin line) conditions.

lateral to the stimulus, and a later phase (225-300 msec) that was more widely distributed and symmetrical. The early contralaterality was reflected in significant interactions of attended location $\times$ visual field $\times$ hemisphere $[F(1,11)=7.88, p<.02]$, and of attended location $\times$ visual field $\times$ hemisphere $\times$ electrode site $[F(5,55)=5.03$, $p<.002]$ for the mean amplitude over $150-225 \mathrm{msec}$ in the difference wave. ${ }^{2}$ This early SN measure also tended to be larger over the left hemisphere $[F(1,11)=9.8, p<$ .01 , for attended location $\times$ hemisphere], particularly for the attend-motion condition $[F(1,11)=16.6, p<.002$, for the attended location $\times$ attended feature $X$ visual field $X$ hemisphere interaction]. The scalp distribution of this early phase of the SN varied with the type of feature being attended; attending to color was associated with greater and more contralateral effects over the occipitotemporal sites, whereas attending to motion resulted in larger and more symmetrical SN amplitudes over the temporal and parietal electrodes $[F(5,55)=9.32, p<$ .001 , for the attended location $\times$ attended feature $\times$ visual field $\times$ hemisphere $\times$ electrode site interaction].

The later phase of the $\mathrm{SN}$ was also substantially larger for feature selections at the attended location $[F(1,11)=$ $7.92, p<.02]$, with larger amplitudes over central and parietal scalp areas $[F(5,55)=8.8, p<.001$, for attended location $\times$ electrode site]. The $\mathrm{SN}$ for motion and color selections differed in their scalp distribution, with the motion SN having a relatively lower amplitude anteriorly and a relatively larger amplitude temporally $[F(5,55)=$ $3.77, p<.05$, for attended location $\times$ attended feature $\times$ 

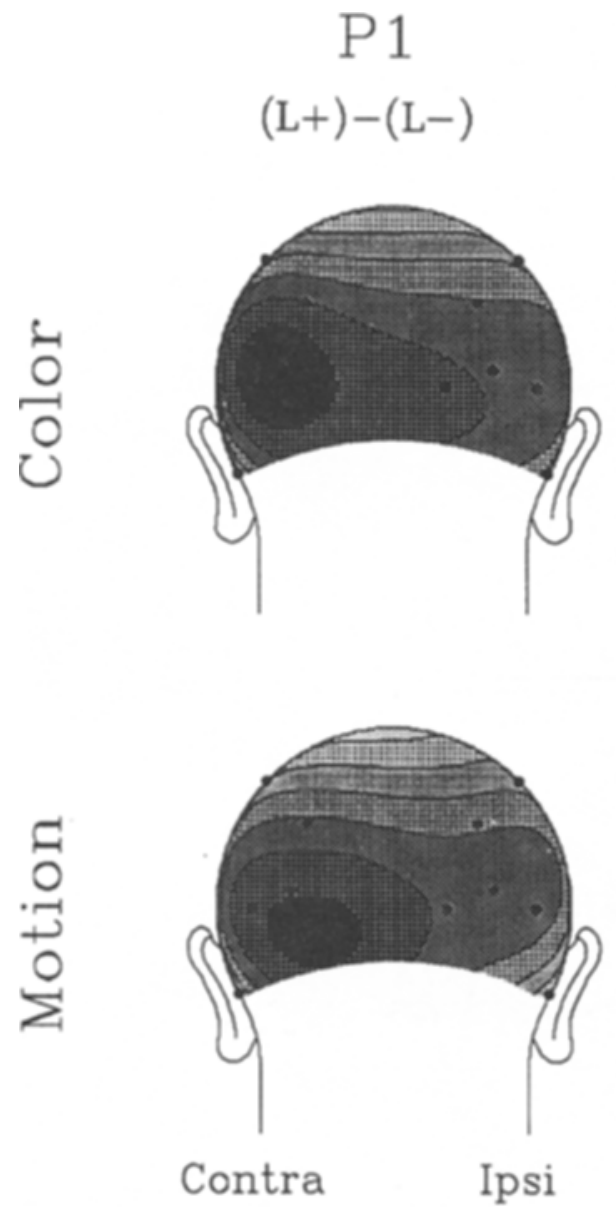
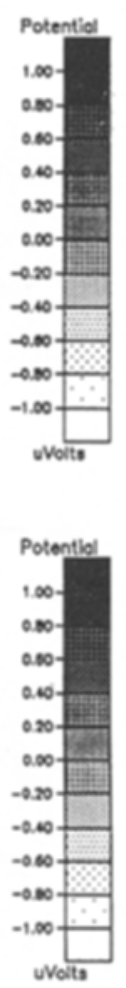

Figure 5. Isovoltage contour maps of the mean amplitude of the P1 (85-120 msec) and N1 (160-190 msec) in the $[(\mathrm{L}+)-$ $(\mathrm{L}-)]$ difference wave, which reflects the amplitude increases of these components produced by spatial selection. Data are averaged across ERPs to left and right field stimuli and across hemispheres, such that the maps shown are organized with the hemisphere contralateral to the stimulus on the left side of each map and the hemisphere ipsilateral to the stimulus on the right side. Note the contralateral scalp distributions of the early phase of the P1 attention effect and the N1 attention effect. electrode site]. These distributions are compared in Figure 8 .

Feature selection was also reflected by a small positive deflection over anterior scalp sites, which peaked at about $210 \mathrm{msec}$ for the attend-color condition and $230 \mathrm{msec}$ for the attend-motion condition. Due to the low amplitude of the SP, comparisons of its peak latency between conditions were not considered reliable; consequently, this component was analyzed as the mean amplitude over the interval 180-220 msec for the attend-color condition and 210-250 msec for the attend-motion condition at frontal and central sites only. The SP was significantly larger for feature selections at the attended location, more so at frontal scalp sites than at central scalp sites $[F(1,11)=30.08, p<.001$, for attended location $X$ electrode site]. There was a tendency for the SP to be larger over the right hemisphere $[F(1,11)=7.03, p<$ .03 , for attended location $\times$ hemisphere].

ERPs to targets. Despite their lower signal-to-noise ratio, the ERP waveforms elicited by the targets showed attentional modulations similar to those observed for the nontarget stimuli during the initial $300 \mathrm{msec}$. Statistical analyses revealed larger amplitudes for targets at the attended location for the $\mathrm{P} 1[F(1,11)=15.04, p<.003]$ and the $\mathrm{N} 1[F(1,11)=57.9, p<.001]$ components over posterior electrode sites, as well as for the anterior $\mathrm{N} 1$ $[F(1,11)=13.02, p<.005]$.

The selection of targets from standard stimuli was reflected in difference waves obtained by subtracting the ERPs evoked by the standards ( $\mathrm{T}-$ ) from the ERPs evoked by the targets $(\mathrm{T}+)$ in each attention condition (Figure 9). These difference waves did not deviate significantly from zero over the first $300 \mathrm{msec}$ poststimulus, indicating that standards and targets were initially processed equivalently for their spatial and feature characteristics. The first indication of target-selective processing appeared in the $\mathrm{N} 2$ deflection, peaking at $325-$ $375 \mathrm{msec}$ in the difference waves, which was larger for $\mathrm{T}+$ than $\mathrm{T}-$ stimuli $[F(1,11)=8.71, p<.01$, for the mean amplitude over $300-400 \mathrm{msec}]$. This $\mathrm{N} 2$ had a maximum 


\section{ATTEND COLOR}

\section{Attended Location $(F+L+)-(F-L+)$}
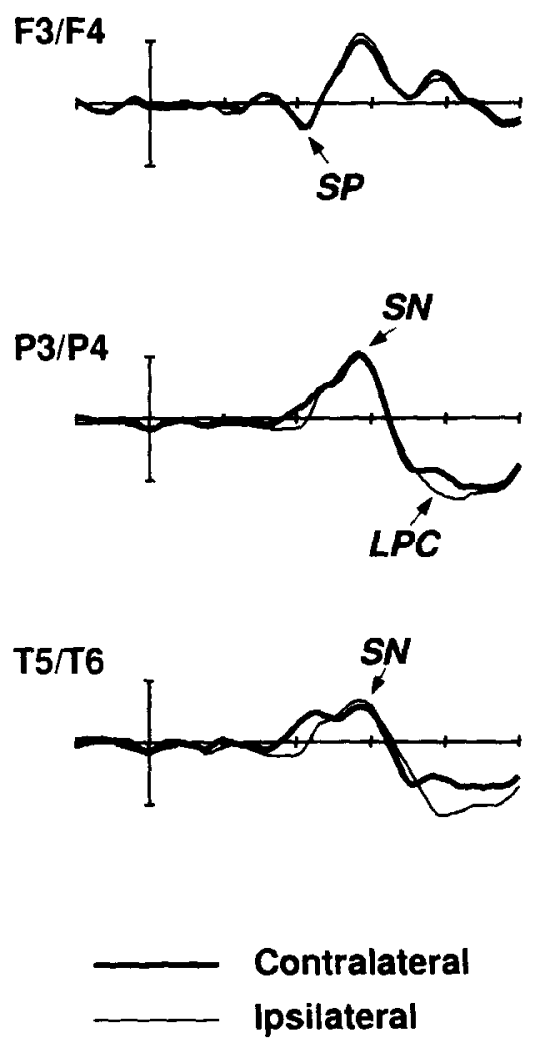

\section{Unattended Location}

$(F+L-)$ - (F-L-)
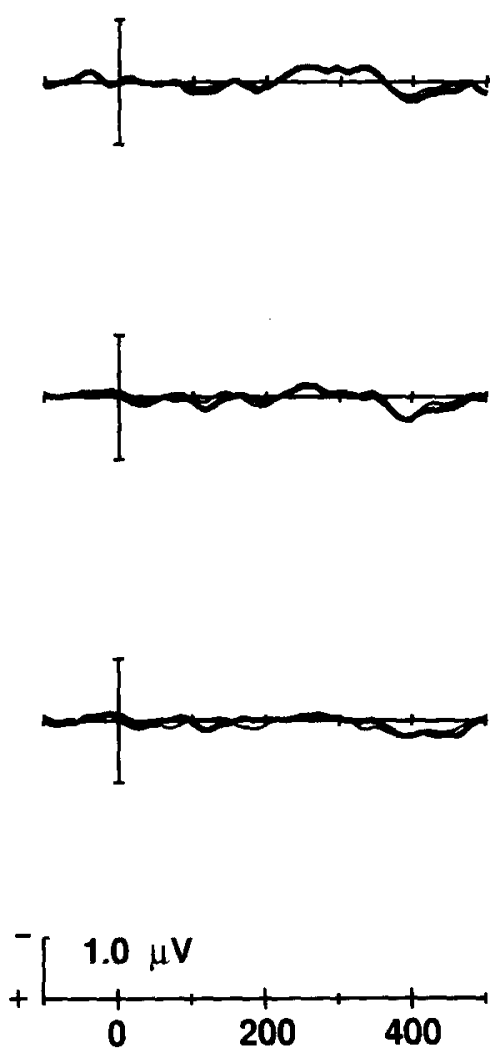

Figure 6. Difference waves associated with the selection of the attended feature value in the attend-color condition, obtained by subtracting average ERPs to standards having the unattended color $(F-)$ from the ERPs to standards with the attended color $(F+)$. Superimposed traces show difference waves for the hemispheres contralateral (thick line) and ipsilateral (thin line) to the stimulus. Left and right columns show difference waves elicited by stimuli at attended $(\mathrm{L}+)$ and unattended $(\mathrm{L}-)$ locations, respectively, collapsed over visual field of stimulus presentation. Note the absence of selection negativity (SN) and selection positivity (SP) in response to stimuli at the unattended location.

amplitude over contralateral central sites $[F(5,55)=5.03$, $p<.001]$ and was significantly greater than zero in the difference waves at both attended $[F(1,11)=7.12, p<$ $.02]$ and unattended $[F(1,11)=5.75, p<.03]$ locations. When measured as the peak negativity in the interval $300-400 \mathrm{msec}$, the $\mathrm{N} 2$ was larger for targets at the attended location than at the unattended location $[F(1,11)=8.23$, $p<.02]$, particularly over central scalp sites $[F(5,55)=$ $5.85, p<.01$, for attended location $\times$ electrode site]. This measure of $\mathrm{N} 2$ was also larger over the hemisphere contralateral to the hemifield of stimulus presentation $[F(1,11)=16.36, p<.002]$. Significantly, the $\mathrm{N} 2 \mathrm{did}$ not differ according to the attended/unattended value of the relevant feature $[F(1,11)=2.47, p<.14$, for feature value; $F(1,11)=0.15, p>.70$, for attended location $\times$ feature value], indicating that selection at this stage was principally based on stimulus location.

The LPC was specifically enlarged for targets at the attended location bearing the attended feature value (i.e., $\mathrm{F}+\mathrm{L}+\mathrm{T}+$ stimuli). This was reflected in a significant interaction (attended location $\times$ feature value) for the mean amplitude measure over 500-700 $\mathrm{msec}[F(1,11)=$ $88.06, p<.001]$. This interaction was also present at the initial phase of the LPC, measured over $400-500 \mathrm{msec}$ $[F(1,11)=27.46, p<.001]$, indicating that target selection contingent on both attended location and attended feature value had taken place by this time. While the LPC was largest in the target difference waves for $\mathrm{F}+\mathrm{L}+$ 


\section{ATTEND MOTION}

\section{Attended Location \\ $(F+L+) \cdot(F-L+)$}
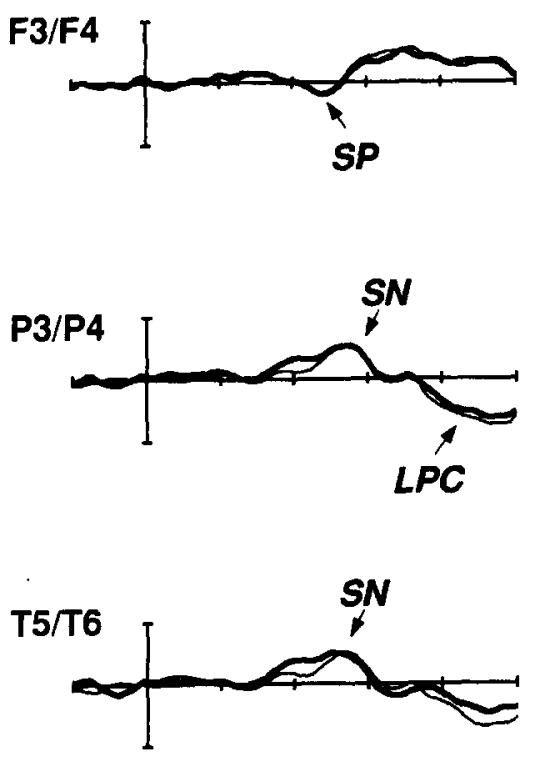

\section{Unattended Location}

$(F+L-)-(F-L-)$
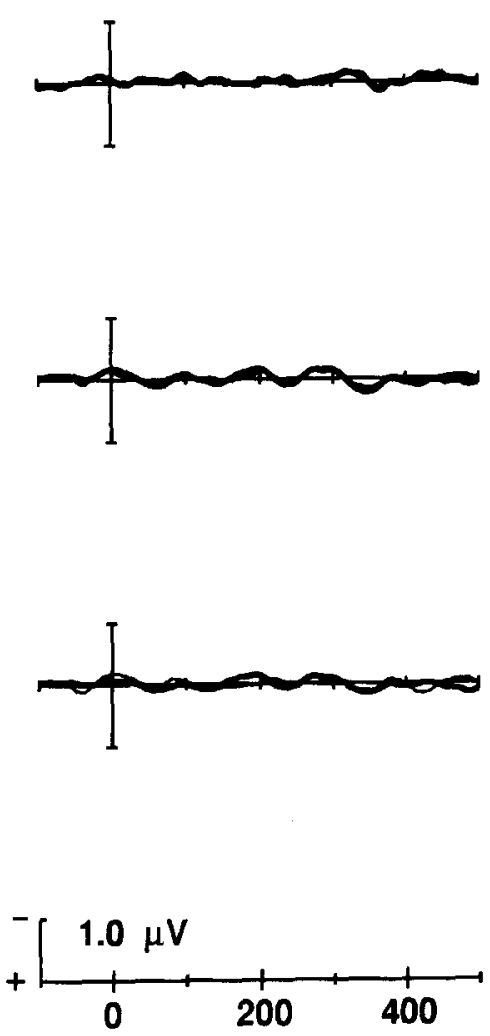

Figure 7. Difference waves associated with the selection of the attended feature value under the attend-motion condition, obtained by subtracting average ERPs to standards moving in the unattended direction $(F-)$ from standards moving in the attended direction $(F+)$. Superimposed traces show difference waves for the contralateral (thick line) and ipsilateral (thin line) hemispheres. Left and right columns show difference waves elicited by stimuli at the attended $(\mathrm{L}+)$ and unattended $(\mathrm{L}-)$ locations, respectively, collapsed over visual field of stimulus presentation.

stimuli, a smaller but significant LPC was also present in the $\mathrm{F}-\mathrm{L}+$ difference wave $[F(1,11)=17.29, p<.001]$.

Hierarchy of selection. The hierarchical organization of the different levels of selection is illustrated in Figure 10. Selection for stimulus location was first evident in the $P 1$ component with an onset of $80-100 \mathrm{msec}$ (arrows in top tracings). This initial spatial selection was reflected in amplitude enhancements of the P1, N1, and P2 waves that were equivalent in both the attend-color and the attend-motion conditions and were not affected by attention to attributes other than location. Feature selection (color or movement direction) was evident at 150-200 msec poststimulus at the onset of the SN (arrows in middle tracings); feature selection was highly contingent on the prior spatial selection, being virtually absent for stimuli at the unattended location. Target se- lection was first evidenced by an N 2 component at 300 $400 \mathrm{msec}$ (arrow 1 in lower tracings of Figure 10), which was more pronounced to targets at the attended location and was not contingent on the stimulus-feature value. Thus, it appears that target selection is carried out in parallel with feature selection at this initial stage. The second stage of target selection was indexed by an LPC that was specifically enlarged to the $\mathrm{F}+\mathrm{L}+\mathrm{T}+$ stimuli, beginning at 400-500 msec (arrow 2 in Figure 10). At this second stage, target selection was hierarchically contingent upon the prior selections of both the relevant location and the relevant feature value. The total absence of LPC at the unattended location in the target difference waves (Figure 9) indicates the effectiveness of spatial selection in eliminating processing of the target-defining feature. In contrast, a small $\mathrm{LPC}$ was present in the $[(\mathrm{F}-\mathrm{L}+\mathrm{T}+)$ 

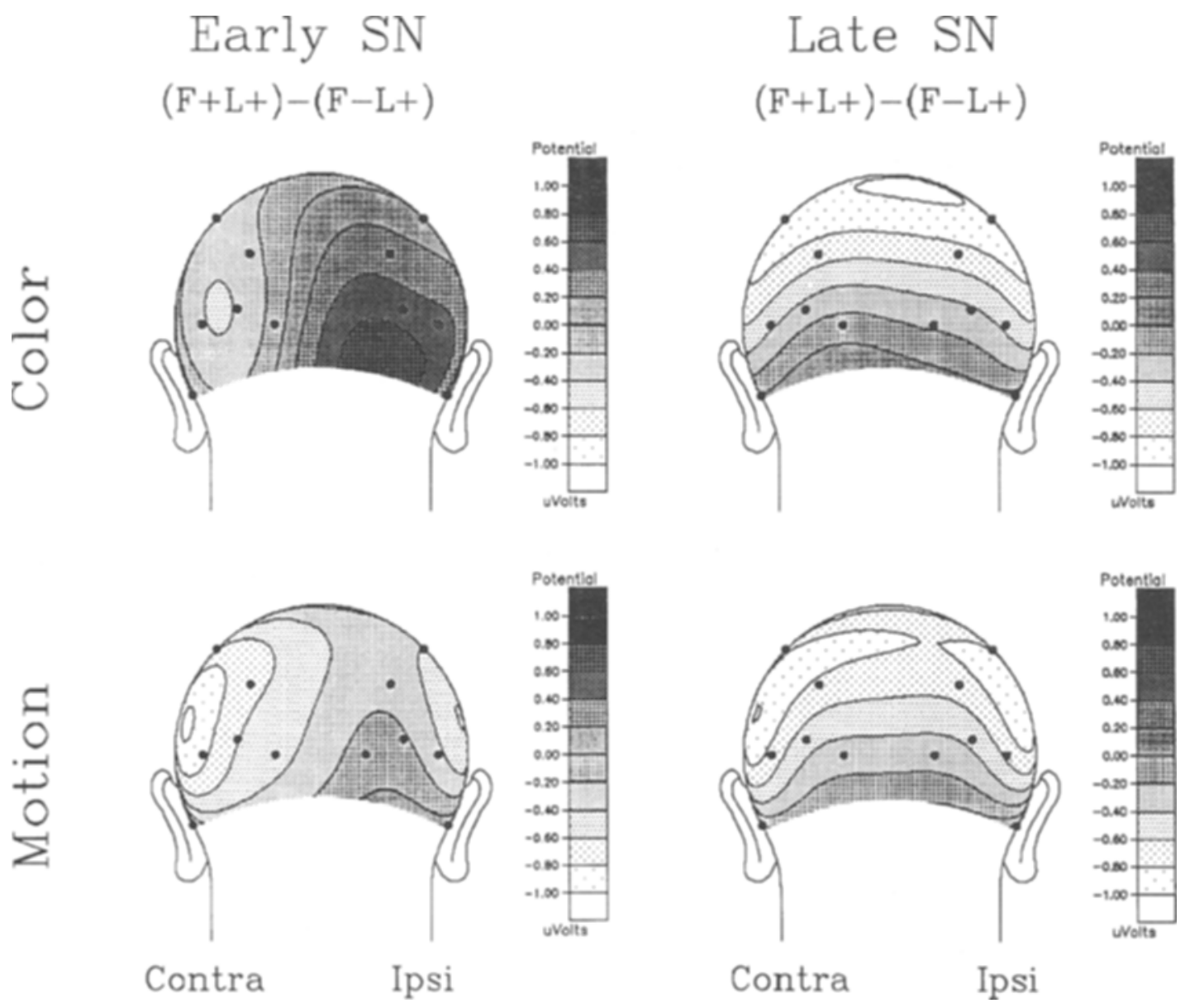

Figure 8. Isovoltage contour maps of the mean amplitude of the early (150-225 msec) and late (225-300 msec) SN in the $[(F+L+)-(F-L+)]$ difference wave, which reflects feature selection at the attended location. As in Figure 5 , maps are based on data averaged across left and right fields and hemispheres so that the hemisphere contralateral to the stimulus appears on the left side and the ipsilateral hemisphere on the right side. Note the change from an early contralateral to a later more symmetrical scalp distribution of the SN.

$-(\mathrm{F}-\mathrm{L}+\mathrm{T}-)]$ target difference waves, suggesting some degree of target-selective processing for attendedlocation stimuli that lacked the attended feature value.

\section{DISCUSSION}

\section{Spatial Selection}

The behavioral results obtained in this study indicate that the subjects were able to focus their attention on the appropriate visual field and to discriminate the relevant features of the moving stimuli. The behavioral selection for location was associated with enhanced amplitude of the early $\mathrm{P} 1$ and $\mathrm{N} 1$ components of the visual ERP in response to stimuli at the attended location. As in previous studies of spatial attention (e.g., Eason et al., 1969; Harter et al., 1982; Hillyard \& Münte, 1984; Mangun et al., 1993; Neville \& Lawson, 1987; Van Voorhis \& Hillyard, 1977), these amplitude modulations had an earlier onset and were initially larger over the hemisphere contralateral to the attended visual field. It is not clear to what extent the difference in $\mathrm{P} 1-\mathrm{N} 1$ amplitudes between stimuli at the attended and unattended locations is a consequence of an active inhibition of unattended field inputs as opposed to a facilitation of attended field positions.

The earliest effect of spatial attention began at about 80 msec poststimulus with the onset of the P1 component. In contrast, the preceding $\mathrm{C} 1$ deflection was not affected by the direction of attention. Several recent studies (Butler et al., 1987; Clark et al., 1995; Mangun et al., 1993) have confirmed early reports (e.g., Jeffreys \& Axford, 1972) that the $\mathrm{Cl}$ component originates in primary visual cortex adjacent to the calcarine fissure. Consistent with these reports, the $\mathrm{Cl}$ negativity obtained in the present study was greatest in amplitude over the ipsilateral medial-occipital cortex, as would be expected for lateral stimuli located above the horizontal meridian (Clark et al., 1995). In contrast with the $\mathrm{C} 1$, the $\mathrm{P} 1$ wave appears to index evoked neural activity in ventral-lateral extrastriate visual cortex of the contralateral hemisphere (Heinze et al., 1994; Mangun et al., 1993). Hence, the dissociation between $\mathrm{Cl}$ and $\mathrm{Pl}$ in their sensitivity to manipulations of spatial attention confirms previous re- 
COLOR
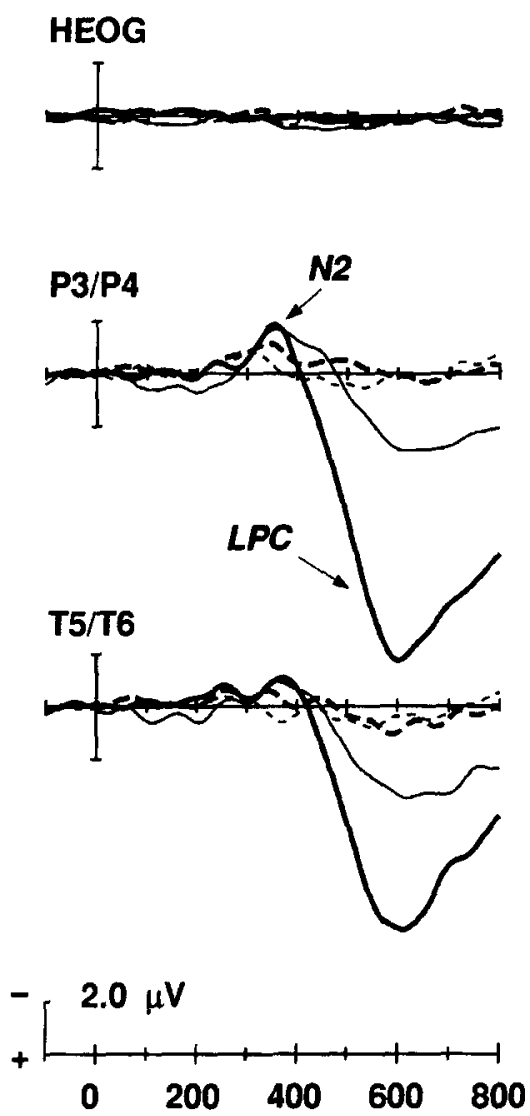

MOTION
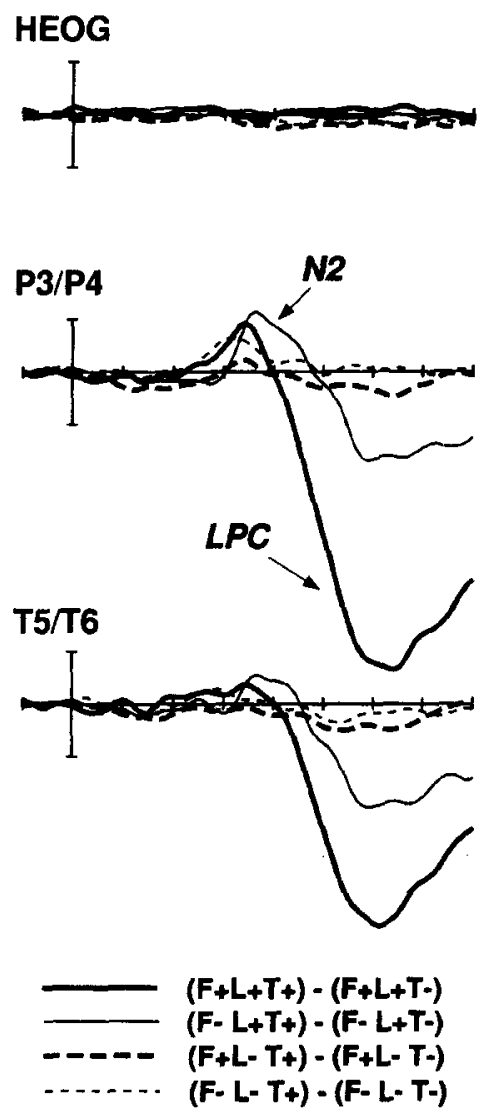

Figure 9. Difference waves obtained by subtracting grand-average ERPs to the standards $(T-)$ from ERPs to the targets $(T+)$ for each of the four types of stimulus combinations indicated in the legend. Separate averages are shown for the attend-color (left column) and attendmotion (right column) conditions. ERPs shown are for the hemisphere contralateral to the visual field of stimulus presentation, collapsed over right and left hemisphere recordings.

ports that evoked neural activity in the primary visual cortex is not modulated by visuospatial attention (Clark \& Hillyard, in press; Gomez et al., 1994). PET studies have similarly failed to demonstrate any differential activation of primary visual cortex as a function of stimulus relevance (Corbetta et al., 1991) or the direction of spatial attention (Corbetta, Miezin, Shulman, \& Petersen, 1993; Heinze et al., 1994).

\section{Feature Selection}

The ERP pattern associated with feature selection differed markedly from that associated with attention to location. The selection of the relevant color was indexed by a broad SN that extended between 150 and $300 \mathrm{msec}$ and an SP that peaked at 200-240 msec at frontal sites. Similar patterns of SN/SP have been observed in previous ERP investigations of attention to color (Harter et al., 1982; Hillyard \& Münte, 1984; Wijers, Lamain, et al., 1989 ) and to other nonspatial features, such as shape, orientation, and spatial frequency (reviewed in Harter \& Aine, 1984; Kenemans et al., 1993), all of which are primarily analyzed by the "ventral" visual pathways that lead to object identification.

A major objective of the present study was to examine the ERP signature of attentional selection based on a stimulus feature presumed to be mediated by "dorsal" visual pathways - the direction of movement of sequentially flashed stimuli. It was found that, as in the case of color selection, the selection of movement direction was also associated with a broad SN and a frontal SP. Both the SN for motion selection and the SN for color selection began with an initial phase (150-200 msec) having greater negativity over the occipitotemporal scalp contralateral to the visual field of stimulus presentation. However, the later phases of the color SN and motion SN differed significantly in scalp distribution and hemispheric lateralization. Whereas the color SN was bilaterally symmetrical and greatest in amplitude over central- 
Selection by: $\quad$ COLOR

LOCATION
MOTION

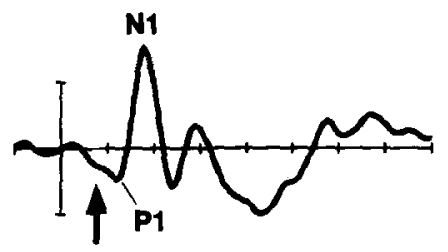

$(L+) \cdot(L-)$

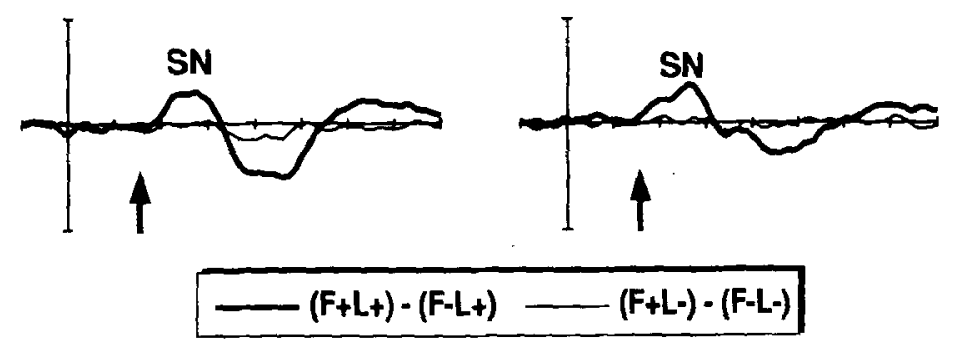

$(F+L-) \cdot(F-L-)$

TARGET
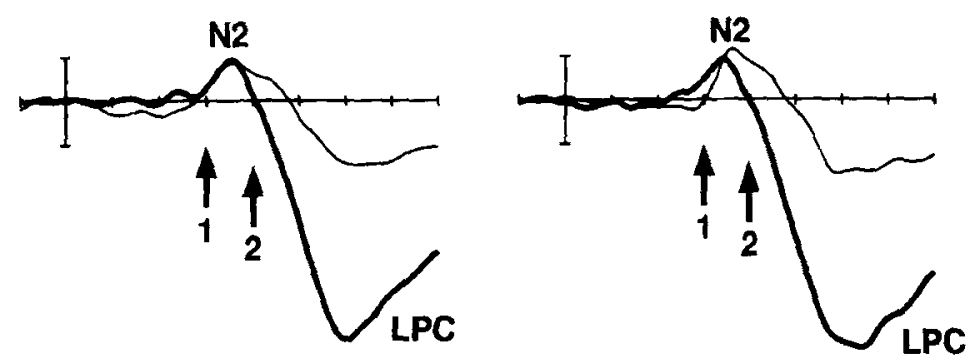

$(F+L+T+) \cdot(F+L+T-)$

$(F-L+T+) \cdot\left(F-L_{+}+T_{-}\right)$
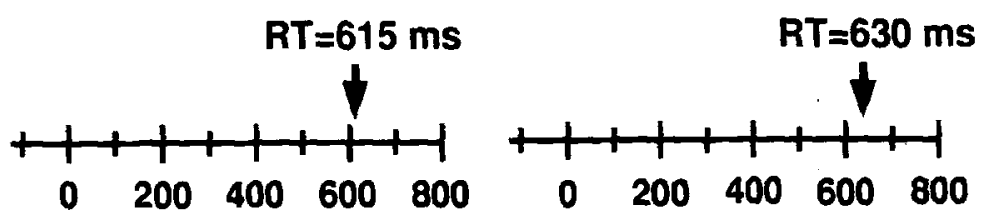

Figure 10. Difference waves reflecting the hierarchical selection of location, feature, and target under the attend-color (left column) and attend-motion (right column) conditions. Selection of the relevant visual field (top row) was reflected in the $[(\mathrm{L}+)-(\mathrm{L}-)]$ difference wave over the contralateral occipitotemporal sites; effects of location selection were evident by $80-100$ msec poststimulus (arrow). Feature selection (middle row) was reflected in the $[(F+)-(F-)]$ difference wave at the attended location $(L+)$ (thick line) and the unattended location $(\mathrm{L}-)$ (thin line) over contralateral temporal sites. Target selection was reflected in the $[(T+)-(T-)]$ difference waves for attended location stimuli at contralateral parietal electrodes. Target selection contingent only on lecation was reflected in the $\mathrm{N} 2$ with an onset of $300-350$ msec (arrow 1), and target selection contingent on both location and feature was evident in the $L P C$ by $400-500$ msec (arrow 2 ). Finally, correct behavioral responses (RTs) averaged $615 \mathrm{msec}$ under the attend-color condition and $630 \mathrm{msec}$ under the attend-motion condition.

parietal areas, the motion $\mathrm{SN}$ was greatest over temporal areas, particularly of the left hemisphere.

One possible interpretation of these topographical differences is that the color and motion SNs arise from separate neural generators, although the limited number of recording sites used here allows only general inferences to be made about possible generator sites. Nonetheless, the scalp distributions observed do appear consistent with separate origins for the color and motion SNs in cortical areas belonging to the ventral and dorsal streams, respectively. In particular, a ventral-occipital area has been identified that responds differentially to stimulus wavelength in humans (Allison et al., 1993; Zeki et al., 1991). A deep dipolar source pointing superiorly in this region 
would be consistent with the broad, centroparietal distribution of the color SN (see Plendl et al., 1993). As for motion perception, there is evidence that the human homolog of area MT is situated relatively more dorsal and lateral than the aforementioned color-sensitive region, at or near the occipitotemporal boundary (Tootell et al., 1995; Watson et al., 1993; Zeki et al., 1991). Bilateral dipolar sources in this region could well account for the more temporal distribution of the motion SN (cf. Probst, Plendl, Paulus, Wist, \& Scherg, 1993).

While further studies are clearly needed to identify the anatomical sources of the various SNs, the present results indicate that selective attention to features analyzed in both dorsal and ventral visual pathways is indexed by an $\mathrm{SP} / \mathrm{SN}$ configuration that is very different from the ERP change associated with spatial attention. Attention to location is manifested by an amplitude modulation of the evoked or exogenous $\mathrm{P} 1$ and $\mathrm{N} 1$ components of the visual evoked potential, whereas selections of elementary nonspatial features including color, spatial frequency, orientation, and movement direction are accompanied by distinct SP/SN components that are only evident in response to stimuli having the attended feature value. This ERP difference is in line with the hypothesis that attention to location operates via qualitatively different mechanisms from attention to other basic visual features (Treisman, 1993; Treisman \& Gelade, 1980; Treisman \& Gormican, 1988).

\section{Selection Hierarchies}

Both the SN for color and the SN for motion were found to be greatly reduced or absent altogether in response to stimuli in the unattended hemifield. A similarly diminished SN for color selection at an unattended location was reported by Hillyard and Münte (1984). The present results indicate that the selective processing of nonspatial features mediated by both dorsal and ventral pathways is contingent upon the prior selection for location. This hierarchical relationship provides strong support for early-selection theories that propose attentional control over the initial processing of stimulus features (e.g., Kahneman \& Treisman, 1984; LaBerge \& Brown, $1989)$ and appears to be inconsistent with the claim of late selection that the different attributes of a stimulus are processed in parallel at all locations (e.g., Duncan \& Humphreys, 1989).

The detection of an infrequent, task-relevant target stimulus is typically accompanied by a late ERP complex consisting of an N2 (also known as N2b or N200) at 200-300 msec and an LPC (also known as P3 or P300) at 300-600 msec (e.g., Ritter, Simson, \& Vaughan, 1983; Wijers, Mulder, Okita, \& Mulder, 1989). In the present study, the N2 component was elicited at $300-350 \mathrm{msec}$ by the target stimuli (i.e., paired flashes with a longer SOA) but was reduced in amplitude for targets at the unattended location. This suggests that analysis of the targetdefining feature (slower apparent motion), like the color and movement-direction features, was also contingent upon spatial selection. It was also found that the N2 elicited by targets at the attended location that lacked the attended feature $(\mathrm{F}-\mathrm{L}+\mathrm{T}+)$ was as large as the $\mathrm{N} 2$ elicited by targets with the attended feature value $(\mathrm{F}+$ $\mathrm{L}+\mathrm{T}+$ ), for both the attend-color and the attend-motion condition. This implies that the target feature of movement speed was processed in parallel, at least initially, with the other relevant feature of color or motion. A similar parallel processing of infrequent target-defining features reflected in the $\mathrm{N} 2$ has been reported by Wijers, Mulder, et al. (1989) and Kenemans et al. (1993). It was only at a later stage of target selection, indexed by the LPC beginning at around $400 \mathrm{msec}$, that target processing became contingent upon the attended value of the color or movement-direction feature.

Previous studies of attention to multifeature stimuli have also identified ERP patterns indicative of separate parallel and hierarchical stages of feature selection. Both Previc and Harter (1982) and Kenemans et al. (1993) found that the SNs elicited by square-wave gratings being selected for spatial frequency and orientation showed an initial pattern of simple additivity, suggesting independent and parallel selection of the two features; at subsequent stages, however, the ERP interaction indicated that the selective processing of orientation was contingent upon the selection of spatial frequency. ${ }^{3}$ In an analogous manner, Wijers, Mulder, et al. (1989) found that the SP/SN associated with the selection of stimulus size was hierarchically dependent upon the selection of the attended color value. In the present study and that of Hillyard and Münte (1984), however, selection for color was found to be contingent upon the earlier selection for location. It seems likely that the degree of independence or contingency between selections of different features would depend in part on their relative discriminability, such that selection of less discriminable features would take place more slowly and become subordinate to selection of more salient features (Hansen \& Hillyard, 1983; Hillyard \& Mangun, 1986). However, behavioral and ERP evidence suggests that selection of nonspatial features is generally contingent upon selection for location (Tsal \& Lavie, 1988, 1993), except when attended and unattended locations are so close together as to be barely discriminable (Hillyard \& Münte, 1984).

\section{Conclusion}

The present ERP findings in conjunction with those of previous studies help reveal the timing and organization of stimulus selection processes while attending to multifeature stimuli. Selection of nonspatial features that are processed in both dorsal and ventral pathways (indexed by the SN/SP and N2/LPC complexes) appears to be hierarchically contingent upon the prior selection of the relevant location (indexed by amplitude modulations of the evoked P1/N1 components). These amplitude modulations suggest that spatial attention acts as an early (80-100 msec) gain control mechanism that enables a more extensive analysis of visual information coming from attended locations (Mangun et al., 1993). Information arising from unattended locations, on the other hand, 
appears to be suppressed or analyzed less fully for its relevant features, as reflected by reduced SP/SN (beginning at $150-200 \mathrm{msec}$ ) and N2/LPC (beginning at 300 $350 \mathrm{msec}$ ) components. These results provide strong support for early-selection theories of attention. For stimuli at the attended location, the selection of the infrequent target feature (movement speed), reflected initially in the $\mathrm{N} 2$ component, proceeds in parallel with the selection of the more frequently presented relevant feature (color or motion). Not until the onset of the LPC at about $400 \mathrm{msec}$ does target processing become contingent upon the features of color or motion direction and thus specific to the targets themselves. Because of the high temporal resolution of ERP recordings, it is possible to study the various levels of contingent and parallel processing well before the ultimate behavioral response at $615-630 \mathrm{msec}$.

\section{REFERENCES}

Albright, T. D. (1984). Direction and orientation selectivity of neurons in visual area MT of the macaque. Journal of Neurophysiology, 52, $1106-1130$.

Allison, A. T., Begleiter, A., McCarthy, G., Roessler, E., Nobre, A. C., \& SPENCER, D. D. (1993). Electrophysiological studies of color processing in human visual cortex. Electroencephalography \& Clinical Neurophysiology, 88, 343-355.

Butler, S. R., Georgiu, G. A., Glass, A. A., Hancox, R. J., Hopper, J. M., \& SMITH, K. R. H. (1987). Cortical generators of the CI component of the pattern-onset visual evoked potential. Electroencephalography \& Clinical Neurophysiology, 68, 256-267.

Clark, V. P., Fan, S., \& Hillyard, S. A. (1995). Identification of early visual evoked potential generators by retinotopic and topographic analyses. Human Brain Mapping, 2, 170-187.

Clark, V. P., \& Hillyard, S. A. (in press). Spatial selective attention affects early extrastriate but not striate components of the visual evoked potential. Journal of Cognitive Neuroscience.

Corbetta, M., Miezin, F. M., Dobmeyer, S., Shulman, G. L., \& Petersen, S. E. (1991). Selective and divided attention during visual discriminations of shape, color, and speed: Functional anatomy by positron emission tomography. Journal of Neuroscience, 11, 23832402.

Corbetta, M., Miezin, F. M., Shulman, G. L., \& Petersen, S. E. (1993). A PET study of visuospatial attention. Journal of Neuroscience, 13, 1202-1226.

DeYoe, E. A., Bandettini, P., Neitz, J., Miller, D., \& Winans, P. (1994). Functional magnetic resonance imaging (FMRI) of the human brain. Journal of Neuroscience Methods, 54, 171-187.

DunCAN, J., \& Humphreys, G. W. (1989). Visual search and stimulus similarity. Psychological Review, 96, 433-458

DunCAN, J., \& HumphreYs, G. [W.] (1992). Beyond the search surface: Visual search and attentional engagement. Journal of Experimental Psychology: Human Perception \& Performance, 18, 578-588.

EASON, R. G., HARTER, M. R., \& White, C. T. (1969). Effects of attention and arousal on visually evoked cortical potentials and reaction time in man. Physiology \& Behavior, 4, 283-289.

ERIKSEN, C. W., \& St. JAMES, J. D. (1986). Visual attention within and around the field of focal attention: A zoom lens model. Perception \& Psychophysics, 40, 225-240.

Felleman, D. J., \& Van Essen, D. C. (1987). Receptive field properties of neurons in area $\mathrm{V} 3$ of macaque monkey extrastriate cortex Journal of Neurophysiology, 57, 889-920.

Gomez Gonzalez, C. M., Clark, V. P., Fan, S., Luck, S. J., \& HillYARD, S. A. (1994). Sources of attention-sensitive visual eventrelated potentials. Brain Topography, 7, 41-51.

Hansen, J. C., \& Hillyard, S. A. (1983). Selective attention to multidimensional auditory stimuli. Journal of Experimental Psychology: Human Perception \& Performance, 9, 1-19.

Harter, M. R., \& Aine, C. J. (1984). Brain mechanisms of visual se- lective attention. In R. Parasuraman \& D. R. Davis (Eds.), Varieties of attention (pp. 293-321). New York: Academic Press.

HARTER, M. R., \& AINE, C. J. (1986). Discussion of neural-specificity model of selective attention: A response to Hillyard and Mangun and to Näätänen. Biological Psychology, 23, 297-311.

Harter, M. R., Aine, C. [J.], \& SChroeder, C. (1982). Hemispheric differences in the neural processing of stimulus location and type: Effects of selective attention on visual evoked potentials. Neuropsychologia, 20, 421-438.

HARTER, M. R., \& GuIDO, W. (1980). Attention to pattern orientation: Negative cortical potentials, reaction time, and the selection process. Electroencephalography \& Clinical Neurophysiology, 49, 461-475.

Harter, M. R., \& Previc, F. H. (1978). Size-specific information channels and selective attention: Visual evoked potential and behavioral measures. Electroencephalography \& Clinical Neurophysiology, 45, 628-640.

Haxby, J. V., Grady, C. L., Horwitz, B., Ungerleider, L. G., Mishkin, M., Carson, R. E., Herscovitch, P., Schapiro, M. B., \& Rapoport, S. I. (1991). Dissociation of object and spatial visual processing pathways in human extrastriate cortex. Proceedings of the National Academy of Sciences of the United States of America, 88, 1621-1625.

Heinze, H. J., Mangun, G .R., Burchert, W., Hinrichs, H., Scholz, M., Münte, T. F., Gos, A., Scherg, M., Johannes, S., Hundeshagen, H., Gazzaniga, M. S., \& Hillyard, S. A. (1994). Combined spatial and temporal imaging of brain activity during visual selective attention in humans. Nature, 372, 543-546.

Hillyard, S. A., Anllo-Vento, L., Clark, V. P., Heinze, H. J., Luck, S. J., \& Mangun, G. R. (in press). Converging operations in the study of visual selective attention. In M. Coles, A. Kramer, \& G. Logan (Eds.), Neuroimaging approaches to the study of visual attention: A tutorial. Washington, DC: American Psychological Association,

Hillyard, S. A., \& Mangun, G. R. (1986). The neural basis of visual selective attention: A commentary on Harter and Aine. Biological Psychology, 23, 265-279.

Hillyard, S. A., Mangun, G. R., Woldorff, M. G., \& Luck, S. J. (1995). Neural systems mediating selective attention. In M. S. Gazzaniga (Ed.), The cognitive neurosciences (pp. 661-681). Cambridge, MA: MIT Press.

Hillyard, S. A., \& MünTE, T. F. (1984). Selective attention to color and location: An analysis with event-related brain potentials. Perception \& Psychophysics, 36, 185-198.

JEFFREYS, D. A., \& AXFORD, J. G. (1972). Source locations of patternspecific components of human visual evoked potentials: I. Components of striate cortical origin. Experimental Brain Research, 16, 1-21.

JOHNSTON, W. A., \& DARK, V. J. (1982). In defense of intraperceptual theories of attention. Journal of Experimental Psychology: Human Perception \& Performance, 8, 407-421.

Kahneman, D., \& Treisman, A. (1984). Changing views of attention and automaticity. In R. Parasuraman \& D. R. Davies (Eds.), Varieties of attention (pp. 29-61). New York: Academic Press.

Kenemans, J. L., KoK, A., \& Smulders, F. T. (1993). Event-related potentials to conjunctions of spatial frequency and orientation as a function of stimulus parameters and response requirements. Electroencephalography \& Clinical Neurophysiology, 88, 51-63.

LABERGE, D., \& BRown, V. (1989). Theory of attentional operations in shape identification. Psychological Review, 96, 101-124.

Luck, S. J., Hillyard, S. A., Mouloua, M., WoldorfF, M. G., Clark, V. P., \& Hawkins, H. L. (1994). Effects of spatial cuing on luminance detectability: Psychophysical and electrophysiological evidence for early selection. Journal of Experimental Psychology: Human Perception \& Performance, 20, 887-904.

Mangun, G. R., \& Hillyard, S. A. (1990.) Allocation of visual attention to spatial locations: Tradeoff functions for event-related brain potentials and detection performance. Perception \& Psychophysics, 47, 532-550.

Mangun, G. R., Hillyard, S. A., \& LuCK, S. J. (1993). Electrocortical substrates of visual selective attention. In D. E. Meyer \& S. Kornblum (Eds.), Attention and performance XIV: Synergies in experimental psychology, artificial intelligence, and cognitive neuroscience (pp. 219-243). Cambridge, MA: MIT Press.

MCCARTHY, G., \& WOOD, C. C. (1985). Scalp distributions of event- 
related potentials: An ambiguity associated with analysis of variance models. Electroencephalography \& Clinical Neurophysiology, 62, 203-208.

Merigan, W. H., \& Maunsell, J. H. (1993). How parallel are the primate visual pathways? Annual Review of Neuroscience, 16, 369-402.

Nakamura, H., Gattass, R., Desimone, R., \& Ungerleider, L. G. (1993). The modular organization of projections from areas $V 1$ and V2 to areas V4 and TEO in macaques. Journal of Neuroscience, 13, $3681-3691$.

NeVille, H. J., \& LAwson, D. (1987). Attention to central and peripheral visual space in a movement detection task: An event-related potential and behavioral study: I. Normal hearing adults. Brain Research, 405, 253-267.

Plendl, H., Paulus, W., Roberts, I. G., Botzel, K., Towell, A., PitMan, J. R., SCherg, M., \& Halliday, A. M. (1993). The time course and location of cerebral evoked activity associated with the processing of colour stimuli in man. Neuroscience Letters, 150, 9-12.

PosNer, M. I. (1980). Orienting of attention. Quarterly Journal of Experimental Psychology, 32, 3-25.

Previc, F. H., \& HARTER, M. R. (1982). Electrophysiological and behavioral indicants of selective attention to multifeature gratings. Perception \& Psychophysics, 32, 465-472.

Probst, A. T., Plendl, H., Paulus, W., Wist, E. R., \& Scherg, M. (1993). Identification of the visual motion area (area V5) in the human brain by dipole source analysis. Experimental Brain Research, 93, 345-351.

RitTer, W., Simson, R., \& Vaughan, H. G. (1983). Event-related potential correlates of two stages of information processing in physical and semantic discrimination trials. Psychophysiology, 20, 168-179.

Sereno, M. I., Dale, A. M., Reppas, J. B., Kwong, K. K., Belliveau, J. W., Brady, T. J., Rosen, B. R., \& Tootell, R. B. H. (1995, May 12). Borders of multiple visual areas in humans revealed by functional magnetic resonance imaging. Science, 268, 889-893.

ToOtell, R. B. H., Reppas, J. R., Kwong, K. K., MalaCh, R., BoRN, R. T., BRady, T. J., Rosen, B. R., \& Belliveau, J. W. (1995). Functional analysis of human MT and related visual cortical areas using magnetic resonance imaging. Journal of Neuroscience, 15, 3215-3230.

Treisman, A. [M.] (1993). The perception of features and objects. In A. D. Baddeley \& L. Weiskrantz (Eds.), Attention: Selection, awareness, and control: A tribute to Donald Broadbent (pp. 5-35). Oxford: Oxford University Press, Clarendon Press.

Treisman, A. M., \& Gelade, G. (1980). A feature-integration theory of attention. Cognitive Psychology, 12, 97-136.

Treisman, A. [M.], \& GormiCaN, S. (1988). Feature analysis in early vision: Evidence from search asymmetries. Psychological Review, 95, 15-48.

Tsal, Y., \& Lavie, N. (1988). Attending to color and shape: The special role of location in selective visual processing. Perception \& Psychophysics, 44, 15-21.

TSAL, Y., \& LAVIE, N. (1993). Location dominance in attending to color and shape. Journal of Experimental Psychology: Human Perception \& Performance, 19, 131-139.

UNGerleider, L. G., \& HAXBY, J. V. (1994). "What" and "where" in the human brain. Current Opinion in Neurobiology, 4, 157-165.

VAN DER HEIJDEN, A. H. C. (1992). Selective attention in vision. London: Routledge.
VAN Voorhis, S., \& Hillyard, S. A. (1977). Visual evoked potentials and selective attention to points in space. Perception \& Psychophysics, 22, 54-62.

VASEY, M. W., \& THAYER, J. F. (1987). The continuing problem of false positives in repeated measures ANOVA in psychophysiology: A multivariate solution. Psychophysiology, 24, 479-486.

Watson, J. D., Myers, R., Frackowiak, R. S., Hajnal, J. V., Woods, R. P., Mazziotta, J. C., ShIPP, S., \& ZeKI, S. (1993). Area V5 of the human brain: evidence from a combined study using positron emission tomography and magnetic resonance imaging. Cerebral Cortex, 3, 79-94.

Wijers, A. A., Lamain, W., Slopsema, J. S., Mulder, G., \& Mulder, L. J. M. (1989). An electrophysiological investigation of the spatial distribution of attention to colored stimuli in focused and divided attention conditions. Biological Psychology, 29, 213-245.

Wijers, A. A., Mulder, G., Okita, T., \& Mulder, L. J. M. (1989). Event-related potentials during memory search and selective attention to letter size and conjunctions of letter size and color. Psychophysiology, 26, 529-547.

Wilson, F. A., O'Scalaidhe, S. P., \& Goldman-Rakic, P. S. (1993, June 25). Dissociation of object and spatial processing domains in primate prefrontal cortex. Science, 260, 1955-1958.

WoLDORFF, M. G. (1993). Distortion of ERP averages due to overlap from temporally adjacent ERPs: Analysis and correction. Psychophysiology, 30, 98-119.

Woods, D. L., \& Alain, C. (1993). Feature processing during highrate auditory selective attention. Perception \& Psychophysics, $\mathbf{5 3}$ 391-402.

Woods, D. L., Alho, K., \& Algazi, A. (1994). Stages of auditory feature conjunction: An event-related brain potential study. Journal of Experimental Psychology: Human Perception \& Performance, 20, 81-94.

Zeki, S., Watson, J. D., Lueck, C. J., Friston, K. J., Kennard, C., \& Frackowiak, R. S. (1991). A direct demonstration of functional specialization in human visual cortex. Journal of Neuroscience, 11, 641-649.

\section{NOTES}

1. The possibility of an independent attention effect on $\mathrm{Cl}$ was tested by measuring its amplitude during its rising phase $(50-75 \mathrm{msec})$, since the positive attention effect on P1 began at about $75 \mathrm{msec}$ and overshadowed any effect that might be present on the late phase of $\mathrm{Cl}$.

2 . These analyses of the $\mathrm{SN}$ were carried out on measures of the difference waves, like those shown in Figures 5 and 6 , in order to simplify the statistics - that is, they include the F+ versus F- comparison. All electrode sites were included, and all analyses involving comparisons of scalp distributions between attend-color and attend-motion conditions were scaled according to McCarthy and Wood (1985).

3. Woods and his colleagues (Woods \& Alain, 1993; Woods, Alho, \& Algazi, 1994) recently found similar ERP patterns in auditory attention tasks, indicating early parallel and late contingent feature selections.

(Manuscript received March 6, 1995; revision accepted for publication July 13, 1995.) 